\title{
The citric acid-modified, enzyme-resistant dextrin from potato starch as a potential prebiotic
}

\author{
Katarzyna Śliżewska \\ Institute of Fermentation Technology and Microbiology, Faculty of Biotechnology and Food Sciences, Technical University of Lodz, Łódź, Poland
}

In the present study, enzyme-resistant dextrin, prepared by heating of potato starch in the presence of hydrochloric $(0.1 \% \mathrm{dsb})$ and citric $(0.1 \% \mathrm{dsb})$ acid at $130^{\circ} \mathrm{C}$ for $3 \mathrm{~h}$ (CA-dextrin), was tested as a source of carbon for probiotic lactobacilli and bifidobacteria cultured with intestinal bacteria isolated from feces of three healthy 70 year old volunteers. The dynamics of growth of bacterial monocultures in broth containing citric acid (CA)-modified dextrin were estimated. It was also investigated whether lactobacilli and bifidobacteria cultured with intestinal bacteria in the presence of resistant dextrin would be able to dominate the intestinal isolates. Prebiotic fermentation of resistant dextrin was analyzed using prebiotic index $(\mathrm{PI})$. In co-cultures of intestinal and probiotic bacteria, the environment was found to be dominated by the probiotic strains of Bifidobacterium and Lactobacillus, which is a beneficial effect.

Key words: resistant dextrin, prebiotic, intestinal bacteria

Received: 14 October, 2013; revised: 25 November, 2013; accepted: 12 December, 2013; available on-line: 29 December, 2013

\section{INTRODUCTION}

The term prebiotic was first introduced in 1995 by Gibson and Roberfroid, defined as "a non-digestible food ingredient that beneficially affects the host by selectively stimulating the growth and/or activity of one or a limited number of bacteria in the colon, and thus improves host health" (Gibson \& Roberfroid, 1995). The definition updated by Gibson specifies that a prebiotic is "a selectively fermented ingredient that allows specific changes, both in the composition and/or activity in the gastrointestinal microflora that confers benefits upon host well-being and health" (Gibson, 2004). The current definition of prebiotics was suggested during the ISAPP experts' meeting in 2008, according to which "a dietary prebiotic is a selectively fermented ingredient that results in specific changes in the composition and/or activity of the gastrointestinal microbiota, thus conferring benefit(s) upon host health" (ISAPP, 2008). For a substance to qualify as a prebiotic, it must meet certain criteria: it must be chemically characterized, exhibit health benefits that are measurable and outweigh any adverse effects, and appropriately modulate the composition or activity of the microbiota in the target host (FAO, 2007; Fuentes-Zaragoza et al., 2011).

Some carbohydrates, such as fructooligosaccharides (FOS) (Roberfroid et al., 2010; Swennen et al., 2006), inulin (Roberfroid, 2007; Van Loo, 2006), transgalactooligosaccharides (TOS) (Davis et al., 2010), and lactulose (Sekhar et al., 2013) are well-accepted prebiotics, while isomaltooligosaccharides (IMO) (Kaneko et al., 1995) and xylooligosaccharides (Crittenden and Playne, 2009) are candidate prebiotics. The fermentation of some oligosaccharides is not as selective as that of FOS, so their prebiotic status remains in doubt. Therefore, there is a need for new prebiotic substances that would significantly and selectively stimulate the growth of lactic acid bacteria, while not being fermented, or only slightly so, by other intestinal bacteria, some of which are pathogenic. The search for functional foods or functional food ingredients is undoubtedly one of the leading trends in today's food industry.

Promising sources of prebiotics are starch products, especially resistant starch (RS) (Nugent, 2005), and products of partial degradation of starch, that is dextrins (Betty, 2010; Leszczyński, 2009; Mermelstein, 2009).

The objective of this study was to determine whether dextrin obtained as a result of heating starch in the presence of citric acid (patent claim no. 392895) is a substance with prebiotic properties (Śliżewska et al., 2010). Thus, it was examined whether such dextrin would be utilized as a source of carbon by probiotic and intestinal bacteria. It was also investigated whether probiotic lactobacilli and bifidobacteria cultured with intestinal bacteria in the presence of resistant dextrin would be able to dominate the intestinal isolates. In the study, the prebiotic index (PI) and the fermentation products of resistant dextrin were determined.

\section{MATERIALS AND METHODS}

Preparation of dextrin. Enzyme-resistant citric acidmodified dextrin (CA-dextrin) was prepared following the method of Kapusniak et al. (2008). Thus, potato starch was sprayed with a hydrochloric acid solution $(0.5 \% \mathrm{w} / \mathrm{v})$ to obtain a final $\mathrm{HCl}$ concentration of $0.1 \%$ on a dry starch basis (dsb). The citric acid solution $(0.5 \%$ $\mathrm{w} / \mathrm{v}$ ) was then added to obtain a final organic acid concentration of $0.1 \% \mathrm{dsb}$. Thoroughly mixed sample was dried at $110^{\circ} \mathrm{C}$ to obtain a final moisture content below $5 \%$. Dried sample $(10 \mathrm{~g})$ was placed in an anti-pressure bottle (SIMAX), capped and heated at $130^{\circ} \mathrm{C}$ for $3 \mathrm{~h}$ in an ELF 11/6 EUROTHERM CARBOLITE oven

e-mail: katarzyna.slizewska@p.lodz.pl

*Presented at the 3-rd Workshop on Microbiology "MIKROBIOT 2013" in Łódź, Poland.

Abbreviations: CA-dextrin, enzyme-resistant citric acid-modified dextrin; CFU, colony-forming unit; dsb, dry starch basis; FAO, Food and Agriculture Organization of the United Nations; FOS, fructooligosaccharides; IMO, isomaltooligosaccharides; ISAPP, International Scientific Association of Probiotics and Prebiotics; PI, prebiotic index; RS, resistant starch; TOS, transgalactooligosaccharides 
(Hope, England). The product was cooled in a desiccator and milled to powder. Dextrin was then washed with $80 \% \mathrm{EtOH}$ to remove an excess of citric acid, and low molecular weight material formed during dextrinization, dried overnight at $50^{\circ} \mathrm{C}$, and then at $110^{\circ} \mathrm{C}$ for $1 \mathrm{~h}$, and finally milled in a cyclone lab sample mill (UDY Corp., USA).

The dynamics of growth of mixtures of bacteria. The intestinal bacteria Lactobacillus, Bifidobacterium, Escherichia coli, Enterococcus, Clostridium, and Bacteroides were cocultured in the presence of resistant dextrin to determine whether the beneficial bacteria Lactobacillus and Bifidobacterium can dominate their environment in the presence of a mixture of isolated intestinal bacteria. Inoculants of bacterial monocultures were prepared in such a way that after $24 \mathrm{~h}$ of growth the number of particular bacteria ranged from $3.50 \times 10^{7}$ to $4.10 \times 10^{7} \mathrm{CFU} / \mathrm{mL}$, corresponding to the number of these bacteria in the terminal section of the ileum (Ouwehand and Vesterlund, 2003). The monocultures of bacteria isolated from three 70-year-old persons were incubated in liquid MRS (Lactobacillus and Bifidobacterium), in liquid VL medium (Clostridium and Bacteroides) and in liquid broth (Escherichia coli and Enterococcus). All monocultures were incubated in sterile $15 \mathrm{~mL}$ test tubes (Marfour) — Lactobacillus, Escherichia coli, Enterococcus under aerobic conditions and Bifidobacterium, Bacteroides and Clostridium under anaerobic conditions. After incubation, the cultures were centrifuged in a MPW-350R centrifuge (Med. Instruments, Poland) at $9000 \mathrm{rpm}$ for $10 \mathrm{~min}$ at $22^{\circ} \mathrm{C}$, the supernatant was decanted and the biomass was transferred to $100 \mathrm{~mL}$ of Wynne et al. (2004) medium with the addition of resistant dextrin (bile salts, $0.5 \mathrm{~g} / \mathrm{l} ; \mathrm{NaCl}, 0.1 \mathrm{~g} / \mathrm{l} ; \mathrm{K}_{2} \mathrm{HPO}_{4}$, $0.04 \mathrm{~g} / \mathrm{l} ; \mathrm{KH}_{2} \mathrm{PO}_{4}, 0.04 \mathrm{~g} / \mathrm{l} ;$ L-cysteine, $0.5 \mathrm{~g} / \mathrm{l} ; \mathrm{Mg}-$ $\mathrm{SO}_{4} \times 7 \mathrm{H}_{2} \mathrm{O}, 0.01 \mathrm{~g} / \mathrm{l} ; \mathrm{NaHCO}_{3}, 0.39 \mathrm{~g} / \mathrm{l}$; Tween, $2 \mathrm{~g} / \mathrm{l}$; peptone $\mathrm{K}, 10 \mathrm{~g} / \mathrm{l} ; \mathrm{MnSO}_{4} \mathrm{x} 4 \mathrm{H}_{2} \mathrm{O}, 0.01 \mathrm{~g} / \mathrm{l}$; hemin, 0.05 $\mathrm{g} / \mathrm{l}$; Vitamin $\mathrm{K}, 0.01 \mathrm{~g} / \mathrm{l}$; resistant dextrin, $10 \mathrm{~g} / \mathrm{l})$. The cultures were incubated for $168 \mathrm{~h}$ under anaerobic conditions (similar conditions as in the intestine). Following dilution in physiological salt, the cultures were plated (Koch's plate method) in duplicate immediately after inoculation $(0 \mathrm{~h})$ and after 24, 48, 72 and $168 \mathrm{~h}$ on selective media: Lactobacillus on Rogosa agar, Bifidobacterium on RCA agar with the addition of the antibiotic dicloxacillin, Escherichia coli on ENDO agar, Enterococcus on bileaesculin agar, Clostridium on DRCM agar and Bacteroides on Schaedler agar with an antibiotic. The plates were in- cubated for $48 \mathrm{~h}$ at $37^{\circ} \mathrm{C}$; Lactobacillus, Escherichia coli, and Enterococcus under aerobic conditions and Bifidobacterium, Bacteroides and Clostridium under anaerobic conditions in a Concept 400 anaerobic chamber (Ruskinn Biotrace, USA).

Determination of prebiotic index (PI). Prebiotic fermentation of resistant dextrins was analyzed using a quantitative equation (prebiotic index - PI). The PI equation is based on the changes in key bacterial groups during fermentation. The bacterial groups incorporated into this PI equation were bifidobacteria, lactobacilli, clostridia and bacteroides. The equation assumes that an increase in the populations of bifidobacteria and/or lactobacilli is a positive effect while an increase in bacteroides and clostridia is negative (Palframan et al., 2003).

The PI equation is described below:

$\mathrm{PI}=($ Bifidobacterium $/$ Total bacteria $)-($ Bacteroides $/$ Total bacteria) + (Lactobacillus/Total bacteria $)-($ Clostridium/Total bacteria).

pH changes. Changes in $\mathrm{pH}$ were monitored with an Elmetron CP-401 pH-meter (Elmetron, Poland).

\section{RESULTS AND DISCUSSION}

It seems likely that prebiotic activity will be exhibited by dextrin obtained by simultaneous thermolysis and chemical modification of potato starch in the presence of a volatile inorganic acid (hydrochloric acid) as a catalyst of the dextrinization process and an excess amount of an organic acid (citric acid) as a modifying factor (patent claim no. 392895 "Preparation with prebiotic qualities"). The enzyme-resistant dextrin, prepared by heating of potato starch in the presence of hydrochloric $(0.1 \%$ $\mathrm{dsb})$ and citric $(0.1 \% \mathrm{dsb})$ acid at $130^{\circ} \mathrm{C}$ for $3 \mathrm{~h}$ (CAdextrin), was tested as a source of carbon for probiotic lactobacilli and bifidobacteria cultured with the intestinal bacteria isolated from the feces of three healthy 70 -yearold volunteers.

In media where CA-dextrin was the source of carbon, all Lactobacillus and Bifidobacterium strains reached the stationary phase at $24 \mathrm{~h}$ of incubation. The number of bacteria of the genus Lactobacillus and Bifidobacterium in the stationary phase was similar and amounted to: $8.59 \log$ $\mathrm{CFU} / \mathrm{mL}$ and $8.42 \mathrm{CFU} / \mathrm{mL}$, respectively. At $168 \mathrm{~h}$ of culture in a medium with dextrin modified with citric
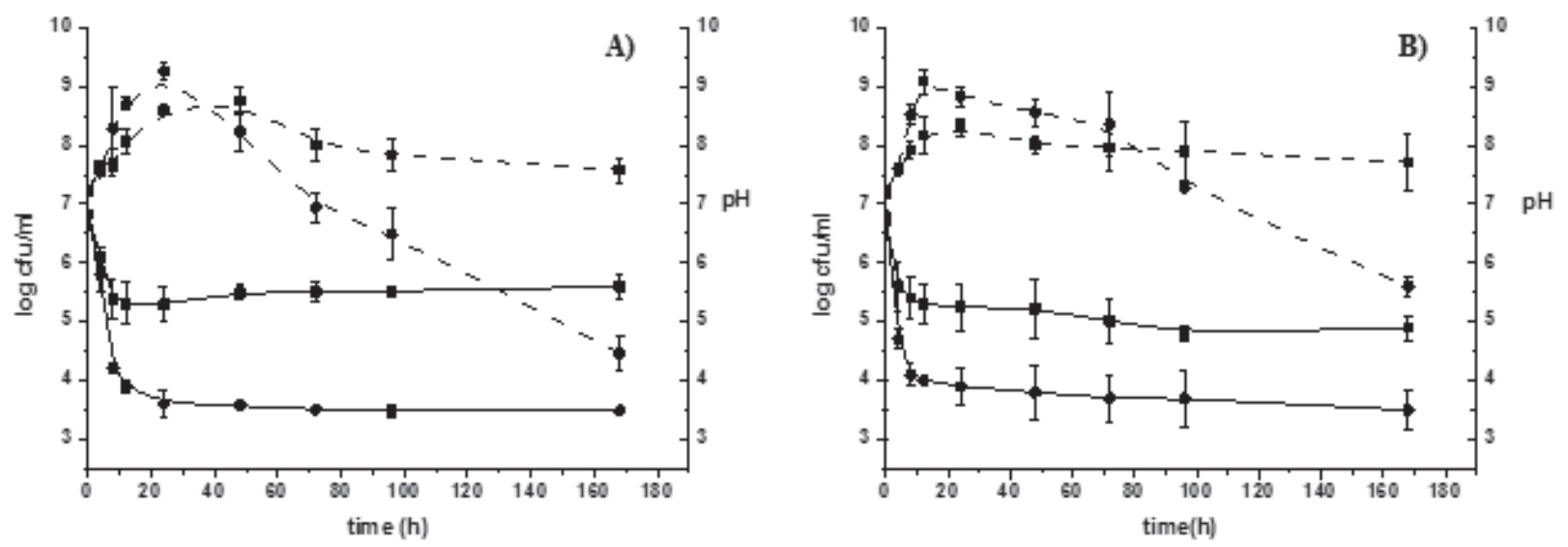

Figure 1. The growth curves (--) and changes in $\mathrm{pH}(-)$ for Lactobacillus (A) and Bifidobacterium (B) bacteria grown in the medium containing CA-dextrin ( $\square$ ) or glucose (control) (O).

Results show means and standard deviations of $n=3$ replicates. 

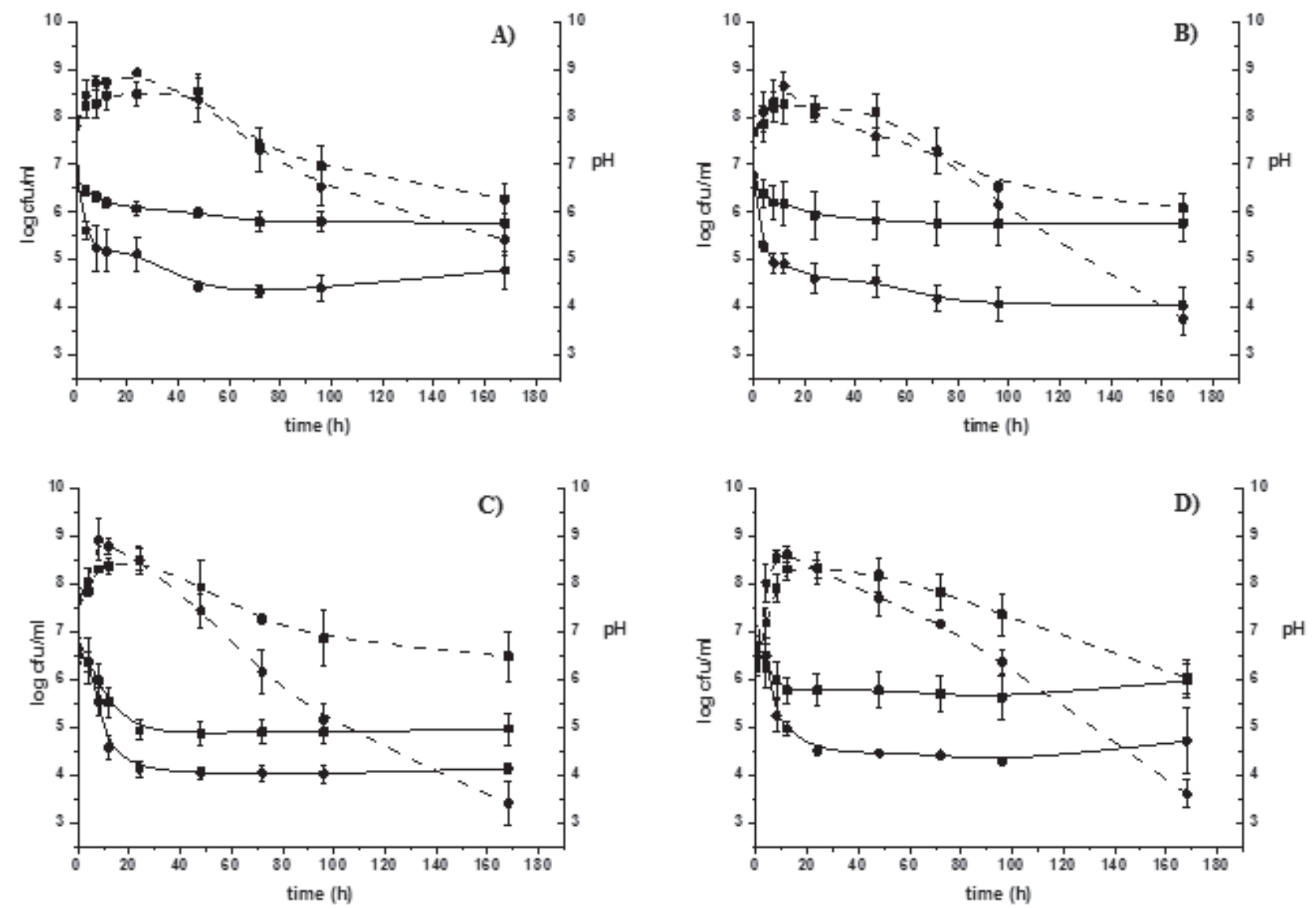

Figure 2. The growth curves (--)and changes in $\mathrm{pH}(-)$ for Bacteroides (A), Clostridium (B), Enterococcus (C) and Escherichia coli (D) bacteria grown in the medium containing CA-dextrin $(\square)$ or glucose (control) $(\bullet)$.

Results show means and standard deviations of $n=3$ replicates.

-acid, the number of lactobacilli and bifidobacteria remained high and ranged from 7.61 to $7.89 \log \mathrm{CFU} / \mathrm{mL}$, which shows their substantial viability (Fig. 1).

Control strains were grown in media with glucose. At $24 \mathrm{~h}$ of incubation, in cultures with glucose the number of lactobacilli and bifidobacteria amounted from 9.15 to $9.40 \log \mathrm{CFU} / \mathrm{mL}$. The bacteria entered the stationary phase, similarly as in media containing dextrin, after 24 $\mathrm{h}$ of incubation. However, the stationary phase lasted much shorter than in media containing dextrin. At 168 $\mathrm{h}$ of culture, the number of viable Lactobacillus and Bifidobacterium cells cultured with glucose was much lower than that of cells cultured with resistant dextrin, and amounted from 4.52 to $5.75 \mathrm{log} \mathrm{CFU} / \mathrm{mL}$ (Fig. 1).

In the medium containing dextrin, the acidifying activity of bifidobacteria was higher than that of lactobacilli. After incubation, a test of culture $\mathrm{pH}$ revealed that $B i$ fidobacterium had the highest acidifying activity $(\mathrm{pH} 4.8)$, while Lactobacillus - the lowest ( $\mathrm{pH}$ 5.6). In the control medium containing glucose, the $\mathrm{pH}$ of Lactobacillus and Bifidobacterium cultures decreased much more than that in the medium containing dextrin; at $168 \mathrm{~h}$ the $\mathrm{pH}$ was 3.50 (Fig. 1).

In media containing CA-dextrin, the other bacteria isolated from human feces were able to grow, but the degree of dextrin utilization depended on the strain. In media with resistant dextrin, bacteria entered the stationary phase between 12 and 48 h of incubation and it lasted for 20-30 consecutive hours. In this phase, the highest cell count was found for Bacteroides strains (8.50 log
$\mathrm{CFU} / \mathrm{mL}$ ) (Fig. 2). Also Enterococcus strains grew successfully, with the number of cells in the stationary phase reaching $8.48 \log \mathrm{CFU} / \mathrm{mL}$. Lower growth was found for Escherichia coli and Clostridium strains (8.30 and 8.25 $\log \mathrm{CFU} / \mathrm{mL}$, respectively) (Fig. 3). In media containing dextrin, bacteria isolated from human feces preserved high viability, and at $168 \mathrm{~h}$ the number of viable cells was larger by $1-2.5 \mathrm{log}$ cycles than that of the control cells grown with glucose.

Out of the bacteria isolated from human feces, the most acidifying ones were Enterococcus strains, which decreased $\mathrm{pH}$ to about 4.90. In cultures containing dex-

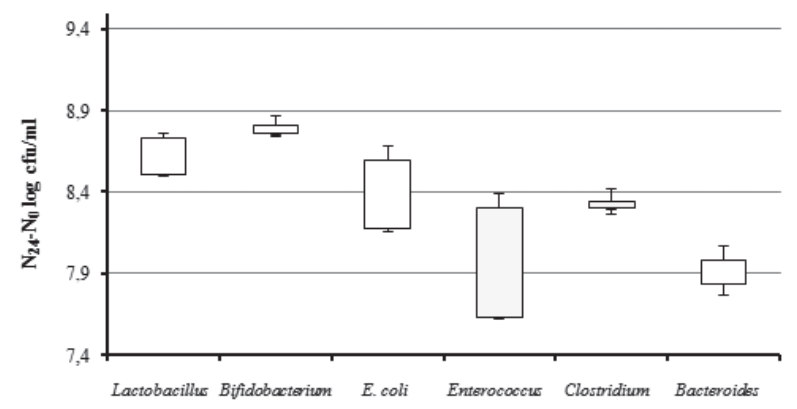

Figure 3. The increase in the number of cells intestinal bacteria $\left(\mathrm{N}_{24}-\mathrm{N}_{0}\right)$ grown together for $24 \mathrm{~h}$ in the medium containing CAdextrin.

$\mathrm{N}_{24}$ - the number of bacterial cells at $24 \mathrm{~h}$ of incubaction $\mathrm{N}_{0}^{24}$ - the number of bacterial cells at incubaction. Results show means and strandard deviations of $\mathrm{n}=3$ replicates. 
trin, no significant differences were found between the remaining strains, as the $\mathrm{pH}$ ranged from 5.70 to 6.20 . Enterococcus strains were most active by $24 \mathrm{~h}$ of incubation, while the others by $12 \mathrm{~h}$ of incubation; later on the $\mathrm{pH}$ values did not change significantly (Fig. 2).

It was shown that all the bacteria isolated from human feces were able to grow and utilize CA-dextrin as a source of carbon, albeit to varying degrees. The highest growth was recorded for Lactobacillus and Bifidobacterium. Bifidobacterium strains were also characterized by the highest acidifying activity (lowering $\mathrm{pH}$ to 4.8 ), which remains consistent with the results reported by other authors (Bielecka et al., 2002; Crittenden et al., 2001). The weakest growth was observed for Clostridium and Escherichia coli. It was found that the stationary phase for Lactobacillus and Bifidobacterium strains was much longer than for other intestinal bacteria. After prolonging the culture time to $72-168 \mathrm{~h}$, which corresponds to a retarded or pathological passage of digesta through the large intestine, the viability of intestinal bacteria in a medium with resistant dextrin was found to be lower by 1-1.5 log cycles than that of Lactobacillus and Bifidobacterium. The number of Lactobacillus, Bifidobacterium, and other bacteria isolated from fecal samples grown in the media containing $1 \%$ glucose was lower by $1-2.5 \log$ cycles than that of corresponding bacteria grown in a medium containing dextrin. This may have been caused by lower $\mathrm{pH}$ values of the controls, under which the culture environment became unfavorable to preserving high viability by the studied bacteria. This may have been also caused by the protective effects of dextrin on the bacteria.

The objective of the study was to determine whether lactobacilli and bifidobacteria co-cultured in the presence of CA-dextrin would be able to dominate over the intestinal bacteria such as E. coli, Enterococcus, Clostridium and Bacteroides. The bacteria were cultured anaerobically at $\mathrm{pH}$ 6.7, under conditions similar to those in the large intestine, using a $10^{7} \mathrm{CFU} / \mathrm{mL}$ bacterial inoculum and a culture time of up to $168 \mathrm{~h}$.

It was shown that after $24 \mathrm{~h}$ of incubation strains isolated from the feces of 70 -year-old subjects were dominated by Lactobacillus and Bifidobacterium. The number of bacterial cells $\left(\mathrm{N}_{24}-\mathrm{N}_{0}\right)$ at $24 \mathrm{~h}$ amounted to $8.50-8.70$ $\log \mathrm{CFU} / \mathrm{mL}$ by Lactobacillus and 8.70-8.80 $\log \mathrm{CFU} /$ $\mathrm{mL}$ by Bifidobacterium (Fig. 3). Escherichia coli was also found to grow well (the number of cells increased to 8.20-8.60 $\log \mathrm{CFU} / \mathrm{mL}$ ). The growth of Enterococcus and Clostridium strains amounted respectively to $7.60-8.30$ $\log \mathrm{CFU} / \mathrm{mL}$ by Enterococcus and $8.30 \log \mathrm{CFU} / \mathrm{mL}$ by Clostridium. There was no increase in the number of cells in Bacteroides strains and after 24 hours of incubation, the number of bacterial cells was at the level of inoculation (Fig. 3).

It was found that higher counts of the studied probiotic bacteria and of bacteria isolated from fecal samples may have been caused by interactions taking place in the mixture, such as multi-level protocooperation or metabiosis, where strains supply each other with nutrients, produce growth substances, or exchange gases. It is also possible that syntrophy occurred, whereby protons were used as electron acceptors. Such fermentation may have led to the production of molecular hydrogen, which could have been transferred from one species of microorganisms to another (Dale and Park, 2010; Ouwehand and Vesterlund, 2003).

It was shown that the PI values in media with CAdextrin were positive; furthermore, the prebiotic index increased with the time of culture (from 0.033 at $24 \mathrm{~h}$ of incubation to 0.176 at $168 \mathrm{~h}$ ), which proves that ben- eficial bacteria (Bifidobacterium and Lactobacillus) can dominate their environment in the presence of a mixture of intestinal bacteria cultured with the addition of resistant dextrin.

The calculated PI values for CA-dextrin were higher than those reported by Olano-Martin et al. (2003) or by Kordyl (2010) for inulin and oligosaccharides under the same incubation conditions (anaerobiosis; $1 \%$ prebiotic addition; $\mathrm{pH}$ 6.8; incubation temperature of $37^{\circ} \mathrm{C}$ ), which shows that CA-dextrin may act as a prebiotic substance.

\section{CONCLUSIONS}

The experiments showed that dextrin obtained as a result of heating potato starch in the presence of hydrochloric acid $(0.1 \%$ of starch dry mass) and citric acid $\left(0.1 \%\right.$ of starch dry mass) at $130^{\circ} \mathrm{C}$ for $3 \mathrm{~h}$ specifically supported growth of probiotic strains of Bifidobacterium and Lactobacillus. However, in order to recognize a potential prebiotic effect of citric acid - modified dextrin additional in vivo studies are required.

\section{Acknowledgements}

The study was supported by the Polish Ministry of Science and Higher Education, Grant No. N N312 3353 39.

The results were presented at the 3rd Workshop on Microbiology „MIKROBIOT 2013” in Lodz, Poland.

\section{REFERENCES}

Betty WLi (2010) Analysis of Dietary Fiber and Nondigestible Carbohydrates. In Handbook of prebiotics and probiotics ingredients. Cho SS, Finocchiaro ET, eds, pp 1-12. CRC Press Taylor \& Francis Group, Boca Raton, United States of America.

Bielecka M, Biedrzycka E, Majkowska A, Juskiewicz J (2002) Effect of non-digestible oligosaccharides on gut microecosystem in rats. Food Res Int 35: 139-144.

Crittenden R, Morris LF, Harvey ML, Tran LT, Mitchell HL, Playne MJ (2001) Selection of a Bifidobacterium strain to complement resistant starch in a symbiotic yogurt. I Appl Microbiol 90: 268-278.

Crittenden RG, PlayneMJ (2009) Prebiotics. In Handbook of probiotics and prebiotics. Lee YK, Salminen S, eds, pp 535-584. John Wiley \& Sons, New Jersey, Canada.

Dale JW, Park SF (2010) Molecular genetics of bacteria. Fifth edition, Wiley-Blackwell, Chichester, UK.

Davis LMG, Martínez I, Walter J, Hutkins R (2010) A dose dependent impact of prebiotic galactooligosaccharides on the intestinal microbiota of healthy adults. Int J Food Microbiol 144: 285-292.

FAO Technical Meeting on Prebiotics (2007) Food Quality and Standards Service (AGNS), Food and Agriculture Organization of the United Nations (FAO). FAO Technical meeting Report, 15-16 September 2007.

Fuentes-Zaragoza E, Sánchez-Zapata E, Sendra E, Sayas E, Navarro C, Fernández-López J, Pérez-Alvarez JA (2011) Resistant starch as prebiotic: A review. Starch/Stärke 63: 406-415.

Gibson GR (2004) Fibre and effects on probiotics (the prebiotic concept). Clin Nutr Suppl 1: 25-31.

Gibson R, Roberfroid M (1995) Dietary modulation of the human colonic microbiota: introducing the concept of prebiotics. J Nutr 125: 140-1412.

IS APP (2008) $6^{\text {th }}$ Meeting of the International Scientific Association of Probiotics and Prebiotics, London, Ontario, 2008.

Kaneko T, Yokoyama A, Suzuki M (1995) Digestibility characteristics of isomaltooligosaccharides in comparison with several saccharides using the rat jejunum loop method. Biosci Biotechnol Biochem 59: 1190-1194.

Kapusniak J, Barczynska R, Slizewska K, Libudzisz Z (2008) Utilization of enzyme-resistant chemically modified dextrins from potato starch by Lactobacillus bacteria. Zesz. Prob Postepón Nauk Rol 530: 445-457 (in Polish).

Kordyl M (2010) Ability of intestinal microorganisms to metabolize prebiotic preparations. Ph.D. Thesis, Technical University of Lodz, 2010 (in Polish).

Leszczyński W (2004) Resistant Starch - classification, structure, production. Pol J Food Nutr Sci 13/54: 37-50. 
Mermelstein NH (2009) Analyzing for resistant starch. Food Technol 4: 80-84.

Nishibata T, Tashiro K, Kanahori S, Hashizume C, Kitagawa M, Okuma K, Gordon DT (2009) Comprehensive measurement of total nondigestible carbohydrates in foods by enzymatic-gravimentric method and liquid chromatography. J Agric Food Chem 57: 76597665.

Nugent AP (2005) Health properties of resistant starch. Br Nutr Bull 30: $27-54$

Olano-Martin E, Gibson GR, Rastall RA (2002) Comparison of the in vitro bifidogenic properties of pectins and pecticoligosaccharides. $J$ Appl Microbiol 93: 505-511.

Ouwehand A, Vesterlund S (2003) Health aspects of probiotics. Investl Drugs J 6: 573-580.

Palframan R, Gibson GR, Rastall RA (2003) Development of a quantitive tool for comparison of the prebiotic effect of dietary oligosaccharides. Lett Appl Microbiol 37: 281-284.

Roberfroid MB (2007) Inulin-type fructans: Functional food ingredients. J Nutr 137: 2493S-2502S.

Roberfroid MB, Gibson GR, Hoyles L, McCartney AL, Rastall R, Rowland I (2010) Prebiotics effects: Metabolic and health benefits. Br J Nutr 104: 1-63.
Sekhar MS, Unnikrishnan MK, Rodrigues GS, Mukhopadhyay C (2013) Synbiotic formulation of probiotic and lactulose combination for hepatic encephalopathy treatment: A realistic hope? Med Hypotheses 81: $167-168$.

Swennen K, Courtin CHM, Delcour JA (2006) Non-digestible oligosaccharides with prebiotic properties. Crit Rev Food Sci Nutr 46: 459-471.

Śliżewska K, Kapuśniak J, Barczyńska R, Libudzisz Z, Jochym K (2010) Polish patent claim P-392895.

Van Loo J (2006) Inulin-type fructans as prebiotics. In Prebiotics. Development and Application. Gibson GR, Rastall RA, eds, pp 57-100. John Wiley and Sons, Chichester, UK

Wynne AG, McCartney AL, Brostoff J, Hudspith BN, Gibson GR (2004) An in vitro assessment of the effects of broad-spectrum antibiotics on the human gut microflora and concomitant isolation of a Lactobacillus plantarum with anti-Candida activities. Anaerobe 10: 165-169. 